\title{
Interactive comment on "Comment on
} "Identification of the IMF sector structure in near-real time by ground magnetic data" by Janzhura and Troshichev (2011)" by Peter Stauning

\section{Peter Stauning}

pst@dmi.dk

Received and published: 30 January 2021

Copenhagen 30 January 2021/PSt

Final Author Comments to ANGEOD discussions on angeo-2020-53

(1) Summary of submitted contribution: P. Stauning: "Comment on "Identification of the IMF sector structure in near-real time by ground magnetic data" by Janzhura and Troshichev (2011)." Angeo-2020-53. 
The main issue in the commentary is the ascertainment that the illustrations and results presented in Janzhura and Troshichev (2011) (J\&T2011) are based on post-event methods in spite of the stated aims in the title, the abstract and in the descriptions of methods to calculate the effects of the solar wind sector structure on polar cap magnetic variations in near-real time.

The contributions from the solar wind sector structure (SS) are important for the calculations of the reference level ("QDC") used in the derivation of the polar magnetic variations providing the basis for polar cap (PC) index values whether in real time or post-event applications.

The post-event QDC methods are used for the "definitive" PC index calculations made at the Arctic and Antarctic Research Institute (AARI) and the Danish Space Research Institute (DTU Space). The near-real time QDC calculations are important for the use of PC indices in space weather monitoring applications. Thus, the J\&T2011 publication is unfortunate for developments of true real-time methods as well as the consolidation of definitive PC index calculations.

As stated in the conclusions: "The commented paper, J\&T2011, and its replica in Troshichev and Janzhura (2012), are significant since along with the publications by Troshichev et al. (2006) and Troshichev et al. (2011) held in chapter 4 of Troshichev and Janzhura (2012), they form the basis for the derivation procedures (Matzka, 2014; Nielsen and Willer, 2019) applied for calculations of Polar Cap (PC) index values in the near-real time and post-event (definitive) versions endorsed by IAGA Resolution \#3 (2013).

However, neither the illustrations nor the results presented in J\&T2011 have been derived by using the specified near-real time methods. The illustrations and results presented in Figs. 1, 6, 7, and 8 display values generated by post-event calculation methods based on using solar sector terms derived from daily median values smoothed over 7 days centred on the day of interest. Figs. 2, 3, and 4 display observed values 
smoothed over 7 days, while the remaining Fig. 5 displays averages over 4 months".

(2) Summary of Interactive Comments angeo-2020-53-SC1.pdf \& Reply angeo-202053-AC1.

In his interactive comment, angeo-2020-53-SC1.pdf, Dr. Troshichev, corresponding author of the commented publication, Janzhura and Troshichev (2011), and first author of its replica in ch. 4.4 "Allowance for IMF sector structure" of Troshichev and Janzhura (2012), makes no attempt to contradict the statements of mingled QDC methods. On the contrary, it seems that Dr. Troshichev denounce the importance of the commented publication (J\&T2011) for the IAGA-endorsed PC index calculations whereby the "definitive" PCN index series extending from 1975 to present calculated by DTU Space is declared invalid.

Further in his interactive comment, angeo-2020-53-SC1.pdf, Dr. Troshichev argues that the method described in Troshichev et al. (2006) "was approved by the IAGA Division V-DAT at a special meeting in Vienna in May 2010". This argument is not seen to be relevant for the present discussion since the Troshichev et al. (2006) methods are not mentioned at all in my submission. The statement, furthermore, is incorrect. According to IAGA V-DAT there was no formal (business) V-DAT meeting in 2010 as such meetings are held during IAGA Assemblies, e.g., in 2009 or 2011. Furthermore, there is no IAGA documentation from a V-DAT meeting held in May 2010.

In his interactive comment, Dr. Troshichev repels publishing the submitted commentary and avoids offering corrections of the commented publication by Janzhura and Troshichev (2011). The bottom line is still that against the title, abstract, and specific statements on the use of near-real time methods, the illustrations and results presented in Figs. 1, 6, 7, and 8 display values derived by post-event QDC calculation methods based on daily median values smoothed over 7 days centred on the day of interest which excludes real-time application.

In summary, it is concluded that the submitted contribution, angeo-2020-53, should be 
published to rectify the inadequate illustrations and to caution against uncritical use of the methods and results presented in the commented publication by Janzhura and Troshichev (2011).

Copenhagen 30 January 2021

Peter Stauning pst@dmi.dk

Interactive

comment

References not included in the submitted commentary.

Nielsen, J. B. and Willer, A. N.: Restructuring and harmonizing the code used to calculate the Definitive Polar Cap Index, Report from DTU Space, 2019. Available at: $\mathrm{ftp}: / / \mathrm{ftp} . \mathrm{space} . \mathrm{dtu} . \mathrm{dk} / \mathrm{WDC} / \mathrm{indices/pcn/} \mathrm{.}$

Troshichev, O. A., Podorozhkina, N. A., and Janzhura, A. S.: Invariability of relationship between the polar cap magnetic activity and geoeffective interplanetary electric field, Ann. Geophys., 29, 1479-1489, https://doi.org/10.5194/angeo-29-1479-2011, 2011.

Interactive comment on Ann. Geophys. Discuss., https://doi.org/10.5194/angeo-2020-53, 2020. 